\title{
Understorey phylogenetic diversity in thermophilous deciduous forests: overstorey species identity can matter more than species richness
}

\author{
Andrea Coppi ${ }^{1}$, Lorenzo Lazzaro ${ }^{1}$, Evy Ampoorter ${ }^{2}$, Lander Baeten ${ }^{2}$, Kris Verheyen ${ }^{2}$ and Federico Selvi ${ }^{3 *}$
}

\begin{abstract}
Background: Understorey vegetation is a key biodiversity component of forest ecosystems. Previous studies examined its relations with the overstorey mainly in terms of taxonomic diversity, composition or productivity. So far, none focused on the phylogenetic aspect, which represents the deepest component of diversity in a community. Here, we explored the relations between overstorey species richness and identity and the phylogenetic structure of the understorey vegetation. As a model system we used a network of 36 plots in thermophilous deciduous forests of central Italy that are part of a European project on forest biodiversity and functions. The plots, characterized by similar site conditions, represent a gradient of overstorey richness from 1 to 4-species mixtures, with variable composition. After surveying the understorey in each plot, measures of phylogenetic diversity and structure (Phylogenetic Diversity, PD; Net Relatedness Index, NRI; and Nearest Taxon Index, NTI) were calculated from a fully resolved seed-plant phylogeny obtained from a ITS-5.8S nrDNA dataset including original sequences from local plant material.

Results: The resulting understorey phylogenetic tree allowed reliable estimation of PD, NRTI and NTI. Phylogenetic diversity was dependent on species richness and the strength of this relationship did not change along the gradient of overstorey tree species richness. Net Relatedness and Nearest Taxon indices were both mostly positive but nonsignificant, indicating random phylogenetic structure of the understorey. The presence of Quercus petraea, usually found in more favorable site conditions, was associated with a significant phylogenetic clustering at the species level.

Conclusions: Overstorey species richness was not related to understorey phylogenetic structure, while species identity (Q. petraea) was associated with an increase in evolutionary relatedness in this forest layer, possibly due to competitive exclusion in favorable site conditions. Further studies should examine whether and how understory phylogenetic structure is affected by variables such as small scale variations in site conditions and presence of a shrub layer, both present but not accounted for in our model system. A better understanding of the role of these variables and their interaction may contribute to fill the current gap between the theoretical field of phylogenetic ecology and forest management.
\end{abstract}

Keywords: Community phylogenetics, Forest biodiversity, Herb layer, Overstorey effects, Phylogenetic clustering, Species identity

\footnotetext{
*Correspondence: federico.selvi@unifi.it

${ }^{3}$ Department of Agriculture, Food, Environment and Forestry, Laboratories of

Botany, University of Florence, Florence, Italy

Full list of author information is available at the end of the article
} 


\section{Background}

Understorey plants play a key role for the diversity of temperate forests, representing up to $80 \%$ of the total species richness of the community (Gilliam 2007). Despite their negligible contribution to the total forest biomass (Welch et al. 2007), they support a number of ecosystem functions and services, such as nutrient and carbon cycles and provision of food and habitat resources (Gilliam 2014; Muller 2014). Hence, maintaining the integrity of the understorey is increasingly acknowledged as a major goal in sustainable forest management and biodiversity conservation programs in Europe (Ministerial Conference on the Protection of Forests in Europe 2011). Several studies have investigated the mechanisms and factors that determine the diversity and composition of the understorey community, mostly in the forests of the central and northern countries (e.g. Mölder et al. 2008; Barbier et al. 2009; Vockenhuber et al. 2011; Verstraeten et al. 2013; Ampoorter et al. 2014, 2015, 2016). Vertical structure and species composition of the overstorey can have major effects on the herb layer, because canopy trees have a species-specific influence on the quality and availability of resources, especially water, nutrients and light, as well as on the physical properties of the litter and soil (Barbier et al. 2008). Most understorey plant species show a high sensitivity to these conditions and respond to variations in tree community structure and composition with changes in abundance, frequency, reproductive efficiency and/or phenological cycles (Verstraeten et al. 2013). However, the effects of overstorey richness and composition are still unclear and cannot be generalized (e.g. Barbier et al. 2008). Some studies in temperate forests have described a generally positive overstorey-understorey diversity relationship and provided support to the environmental heterogeneity hypothesis (Mölder et al. 2008; Vockenhuber et al. 2011). This means that the mixing of tree species and their additive identity effects results in a fine-scale mosaic of environmental conditions at the stand level, which promotes the coexistence of more understorey species (Huston 1979; Silvertown 2004; Levine and Hille Ris Lambers 2009). On the other hand, recent studies across European forests found negative or neutral effects and corroborated the "novel environment creation" hypothesis, by which the mixing of tree species leads to new conditions as a result of averaging of tree species effects or interactive effects between these species (Ampoorter et al. 2015, 2016).

However, previous studies dealing with overstoreyunderstorey relationships focused on taxonomic or functional diversity in especially central European forests, whereas no investigations have considered the phylogenetic dimension so far. According to Faith (1992), phylogenetic diversity (PD) can be defined as the total amount of evolutionary distance among plant species in a community. Such a "deep" component of diversity has been suggested to be relevant for ecosystem services (Faith et al. 2010), stability (Cadotte et al. 2013) and functional processes such as species interactions and resource use (Srivastava et al. 2012). In addition, preserving and maximizing phylogenetic diversity within and across communities is considered one of the most important goals in conservation biology, since this may enhance stability under changing habitat conditions across ecologic and evolutionary time scales (Rodrigues and Gaston 2002). Hence, gaining new insights into the organization of forest communities from an evolutionary perspective and understanding the drivers of understorey PD and structure may have relevant implications for their conservation in the long-term. While previous studies have examined how these components are affected by climate (Tallents et al. 2005; Zhang et al. 2016), disturbance by fragmentation (Arroyo Rodríguez et al. 2012) and biotic invasion (Lapiedra et al. 2015; Selvi et al. 2016), the role of potential biotic filters such as overstorey tree species richness and/ or identity is still unknown (Garnier et al. 2015). This gap has disadvantageous implications for forest management, since silviculture acts directly on species richness and composition of the canopy with unpredictable consequences on understorey phylogenetic structure. In particular, it is unknown whether favoring monocultures of given overstorey trees or mixed stands may influence the level and patterns of evolutionary relatedness in the herbaceous layer. This study represents a first attempt to fill this gap by using thermophilous deciduous forests as model system. To date, little attention has been paid to overstorey-understorey relationships in this important Euro-Mediterranean forest type. Compared with broadleaf forests at more northern latitudes in Europe, this is characterized by relatively high diversity of woody species in the dominant (mainly Quercus sp. pl.), subdominant (Acer, Fraxinus, Ostrya, Sorbus, etc.) and shrub layers (Barbati et al. 2007; Carrari et al. 2016), which may involve different mechanisms and responses in the understorey.

Here, we first investigated the relation between understorey $\mathrm{PD}$ and species richness along a gradient of overstorey species richness. In most plant assemblages PD covaries with species richness (Forest et al. 2007; Qian et al. 2014), but deviations from expected values based on the number of species can occur depending on site conditions and environmental filters (Knapp et al. 2008; Potter and Woodall 2014). We assume that if microhabitat differentiation is increased in the understorey of mixed thermophilous deciduous forests, as generally predicted by the environmental heterogeneity hypothesis for stands with more tree species, deviations may occur because this will favor species that are evolutionarily (and functionally) distant to each other. These species will thus cause overall understory PD to increase more rapidly 
compared to the effect of more closely related species that are expected to occur in the more homogenous environment of pure stands or species-poor mixtures. In terms of phylogenetic structure, overstorey species richness and consequent broader range of niches available in the lower layers should translate into an increase of phylogenetic evenness in the understorey. In fact, distantly related species are likely to better exploit complementary niches and reduce reciprocal competition thanks to their more widely differentiated traits and environmental requirements, compared to closely related species (Wiens et al. 2010; Garnier et al. 2015). This is supported by the Niche Conservatism assumption (Harvey and Pagel 1991; Prinzing et al. 2001), which predicts retention of ecological traits over time among related species and increase of phylogenetic clustering following coexistence in the same community (Webb et al. 2002). Under the novel environment creation hypothesis, instead, the new conditions created by the mixing of more interacting tree species do not allow to predict variations in the phylogenetic structure of the community, which may remain unaltered or becoming either more clustered or over-dispersed.

However, both phylogenetic diversity and structure of the understorey can be affected by overstorey species identity, rather than richness (Selvi et al. 2016). In fact, each tree species acts as a more or less selective biotic filter depending on how it modifies the local conditions through its trait values ("species identity effect"; Kirwan et al. 2009). In principle, the stronger this filter, the higher the level of phylogenetic clustering can be expected under the Niche Conservatism assumption. On the other hand, there is evidence that phylogenetic dispersion can be limited also in favorable habitats without strong filters, due to mechanisms of competitive exclusion that often limits also species richness (Mayfield and Levine 2010).

This paper investigates the issues above using a tree diversity-oriented network of research plots in thermophilous deciduous forests of central Italy as model system. This was designed ad-hoc for the FunDivEUROPE exploratory platform to allow the separate analysis of diversity versus identity (and compositional) effects on various ecosystem functions, while controlling as much as possible for variation in environmental factors (Baeten et al. 2013). After the field inventory of the understorey community in these plots, we built a phylogenetic tree of seed plants in this layer using a DNA sequence dataset including accessions from public databases and original gene sequencing work performed on plant material collected in the sampling sites. As in a recent study (Selvi et al. 2016) such an approach allowed to obtain a fully resolved phylogeny and reliable indices of understorey phylogenetic diversity and structure. To sum up, the specific aims of this study were: (i) to test whether the relationship between understorey species richness and PD varies along a gradient of canopy species richness; (ii) to examine the link between overstorey species richness and understorey phylogenetic structure in relation to the environmental heterogeneity or novel environment creation hypothesis; and (iii) to evaluate the role of major overstorey tree species in our model system in shaping the phylogenetic structure of the understorey.

\section{Methods}

Study site, sampling design and data collection

The study area is located in the Colline Metallifere area of Tuscany in central Italy (Lat. $43.2^{\circ} \mathrm{N}$, Long. $11.2^{\circ} \mathrm{E}$ ), at an altitude of $260-525 \mathrm{~m}$ a.s.l. (Fig. 1). Vegetation data
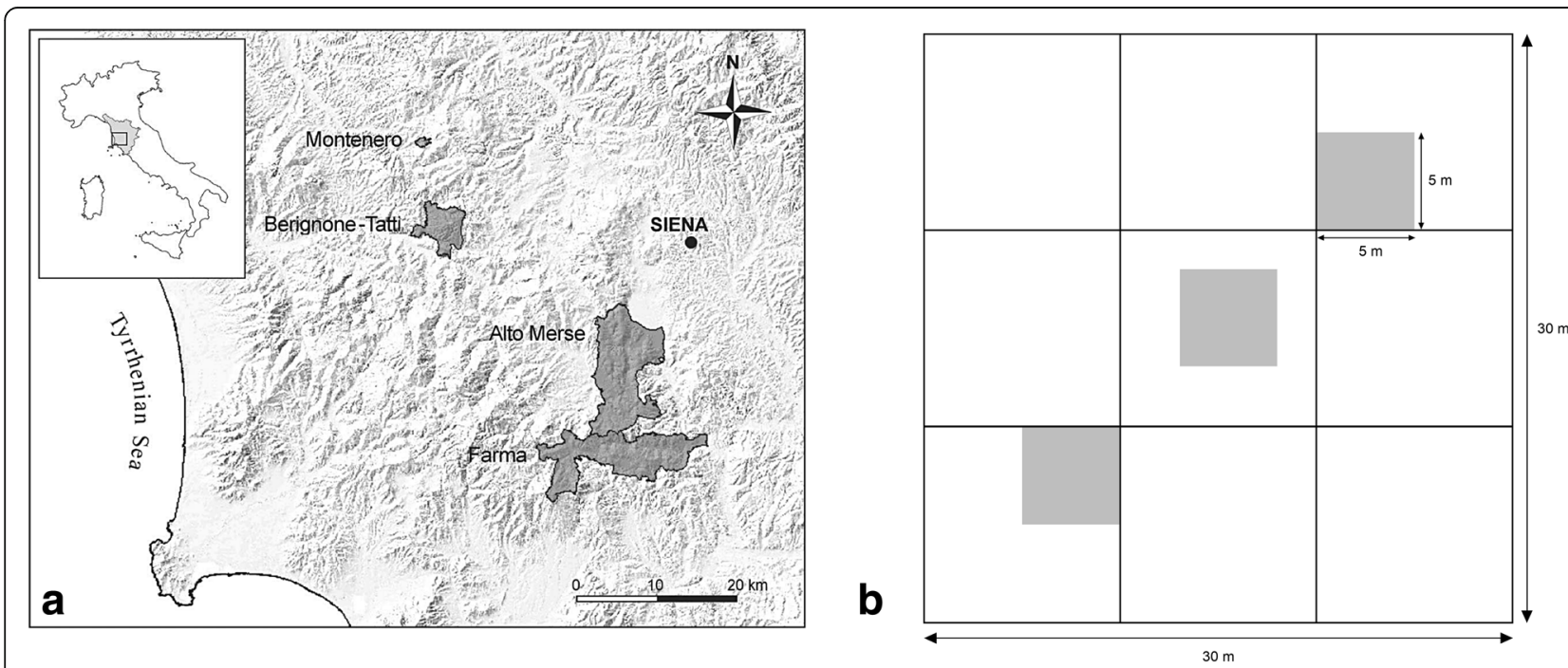

Fig. 1 a Location of the study area in Italy, with indication of the Nature Reserves including the plots; $\mathbf{b}$ plot scheme with ten subplots and the three quadrats used for understorey vegetation analysis 
were collected in a network of 36 permanent forest plots of $30 \mathrm{~m} \times 30 \mathrm{~m}$, subdivided each in 9 subplots of $10 \mathrm{~m} \times$ $10 \mathrm{~m}$ for the purposes of other sampling campaigns in the FunDivEUROPE project. The plots are representative of the category of "thermophilous deciduous forests" as defined in the European Environment Agency classification (EEA), which covers large areas especially in Italy (40\% of the ICP Level I plots) and the Balkans (Barbati et al. 2007). The plots were included in nearly mature stands that originated from the abandonment of the traditional coppice management, that occurred at least 50 years ago, and are mostly included in nature reserves and/or in the Rete Natura 2000 sites (Bussotti et al. 2012; Fig. 1). All details about the guiding criteria of the experimental design of the FunDivEurope exploratory platform and the selection of plots can be found in Baeten et al. (2013). To sum up, Italian plots were selected to cover a tree species richness gradient from 1 to 5 dominant tree species with diverging traits, here named "focal trees": Quercus cerris, Q. ilex, Q. petraea, Castanea sativa and Ostrya carpinifolia. The number of plots for each species richness level was 10 (pure stands), 9 (2-sp. and 3-sp. mixtures), 7 (4-sp. mixtures) and 1 (5-sp. mixtures). For the purpose of this work, the only 5 -species mixture plot was pooled together with the 4-species plots. Each species richness level was replicated with different species combinations of these trees to be able to separate species diversity from composition effects; the 22 species combinations represented in our design and the frequency of each species in the four richness levels are given in Table 1. Basal area proportions between the different tree species in the mixed plots were within predetermined thresholds (given in Baeten et al. 2013) to ensure species a minimum evenness and avoid strong dominance of only one species. While plot selection was focused on dominant canopy trees, other sub-dominant woody species such as Fraxinus ornus L., Sorbus torminalis (L.) Crantz, Ilex aquifolium L., Arbutus unedo L. and others were usually admixed with the above dominant trees for not more than $10 \%$ of the total basal area; this significantly increased species richness in the layers $>1.3 \mathrm{~m}$. In addition, a shrub layer usually $<4 \mathrm{~m}$, with ground cover of $1 \%-30 \%$, and formed by moderately shade-tolerant species such as Cornus mas L., Crataegus laevigata (Poir.) DC., Phillyrea latifolia L., Ligustrum vulgare L., Juniperus communis L. and others was present in most of the plots, as typical in thermophilous deciduous forests of southern Europe (Carrari et al. 2016). The tree regeneration layer over $1.3 \mathrm{~m}$ height was instead very sparse, and hence not likely to affect the understorey.

Environmental variables (soil, topography, altitude) were kept as constant as possible among the sites, to avoid significant covariation between the diversity gradient and environmental variables. To sum up, plots
Table 1 Overview of the number of plots $(N)$ for each combination of focal tree species (numbers in the matrix); the frequency of each species is given for each species richness level (SR) and for the entire set of plots (overall)

\begin{tabular}{|c|c|c|c|c|c|}
\hline & Q. cerris & Q. ilex & Q. petraea & C. sativa & O. carpinifolia \\
\hline \multirow[t]{5}{*}{$S R=1(N=10)$} & 2 & & & & \\
\hline & & 2 & & & \\
\hline & & & 2 & & \\
\hline & & & & 2 & \\
\hline & & & & & 2 \\
\hline Freq. & 2 & 2 & 2 & 2 & 2 \\
\hline \multirow[t]{9}{*}{$S R=2(N=9)$} & 1 & 1 & & & \\
\hline & 1 & & 1 & & \\
\hline & & 1 & 1 & & \\
\hline & 1 & & & 1 & \\
\hline & & 1 & & 1 & \\
\hline & & & 1 & 1 & \\
\hline & 1 & & & & 1 \\
\hline & & 1 & & & 1 \\
\hline & & & & 1 & 1 \\
\hline Freq. & 4 & 4 & 3 & 4 & 3 \\
\hline \multirow[t]{8}{*}{$\mathrm{SR}=3(N=9)$} & 1 & 1 & 1 & & \\
\hline & 1 & 1 & & 1 & \\
\hline & 2 & & 2 & 2 & \\
\hline & & 1 & 1 & 1 & \\
\hline & 1 & 1 & & & 1 \\
\hline & 1 & & 1 & & 1 \\
\hline & & 1 & 1 & & 1 \\
\hline & & 1 & & 1 & 1 \\
\hline Freq. & 6 & 6 & 5 & 4 & 4 \\
\hline \multirow[t]{5}{*}{$S R=4-5(N=8)$} & 2 & 2 & 2 & 2 & \\
\hline & 2 & 2 & 2 & & 2 \\
\hline & 2 & 2 & & 2 & 2 \\
\hline & & 1 & 1 & 1 & 1 \\
\hline & 1 & 1 & 1 & 1 & 1 \\
\hline Freq. & 7 & 8 & 6 & 6 & 6 \\
\hline Overall freq. & 19 & 20 & 16 & 16 & 15 \\
\hline Freq. (\%) & 52.8 & 55.6 & 44.4 & 44.4 & 41.7 \\
\hline
\end{tabular}

were located at an altitude range of $250-520 \mathrm{~m}$ a.s.l., mostly on $\mathrm{N}$-facing slopes with low to average inclination $\left(5-20^{\circ}\right)$; they were all included in a submediterranean climatic area with $800-900 \mathrm{~mm}$ of mean annual rainfall, and $12.5-13.5^{\circ} \mathrm{C}$ of mean annual temperature. Bedrock was almost exclusively of siliceous nature, mainly quartzitic sandstones, and the dominant soil type was Cambisol. Using permutational analysis of variance, Carrari et al. (2016) showed no significant differences between plots in terms of site and soil conditions and stand structure characteristics. However, small scale 
variations were unavoidable due to the complex geomorphology of our hilly region and the long-lasting anthropic activities in the forests. Understorey data collection followed the protocol described in Ampoorter et al. (2016): in each plot, three $5 \mathrm{~m} \times 5 \mathrm{~m}$ sampling quadrats were placed in three distinct subplots at a regular distance along a diagonal from the lower left corner to the upper right corner, respectively (Fig. 1); this design allowed to minimize the edge effect and to sufficiently account for the heterogeneity of micro-topographic conditions inside the plot. However, major heterogeneities such as large tree trunks, tracks and paths, streams and ponds, peaty pools, boulders and cliffs were excluded from the quadrats, so that only terricolous plants growing on mineral and organic soil of the undisturbed forest floor were present. In May 2012 all vascular understorey species $(<1.3 \mathrm{~m})$ in the 108 quadrats were recorded and scored for percentage of ground cover. Mean values of the three quadrats were used to represent the respective plot in the following analyses.

\section{Molecular analyses, sequence alignment and phylogeny construction}

Phylogenetic diversity of the spermatophyte communities in the plots (e.g, excluding four fern species) was inferred from a fully resolved super-tree that we built using three markers from the Internal Transcribed Spacers of the nrDNA, the ITS1, 5.8S and ITS2 regions. These are by far the most widely used for phylogenetic inference and barcoding in spermatophytes ( $\mathrm{Li}$ et al. 2011), allowing us to assemble the sequence dataset retrieving accessions of most species in our plots from the GenBank. Also, the (generally) greater discriminatory power of ITS-5.8S over other genomic regions at the species level (Hollingsworth et al. 2011), allowed to avoid polytomic groups and to resolve relationships even in those genera with two or more species in our dataset (e.g., Quercus, Carex, Vicia, and others). Although recently developed synthesis trees work well in many cases ( $\mathrm{Li}$ et al. 2018), this option would have not provided a full resolution of species-level relationships in our case, and was therefore not adopted.

Sequence data for 103 out of 109 species in our vegetation sample were taken from GenBank (http://www.ncbi.nlm. nih.gov/), using the accession numbers in Additional file 9.

Hence, isolation of genomic DNA was performed for six understorey species that were not available from the latter database: Cruciata glabra (L.) Opiz (Rubiaceae), Dioscorea communis (L.) Caddick \& Wilkin (Dioscoreaceae), Hieracium racemosum Waldst. et Kit. (Asteraceae), Melica uniflora Retz. (Poaceae), Rubus hirtus Waldst. et Kit. (Rosaceae), Ruscus aculeatus L. and Scilla bifolia L. (Asparagaceae). Isolation followed a modified $2 \times \mathrm{CTAB}$ protocol (Doyle and Doyle 1990) while ITS amplification was performed using the primers ITS4 and ITS5 (White et al. 1990). Polymerase chain reactions were performed in a total volume of $25 \mu \mathrm{L}$ containing $2.5 \mu \mathrm{L}$ of $10 \times$ reaction buffer (Dynazyme II, Finnzyme, Espoo, Finland), 1.5 $\mathrm{mmol} \cdot \mathrm{L}^{-1} \mathrm{MgCl}_{2}, 10 \mathrm{pmol}$ of each primer, $200 \mu \mathrm{mol} \cdot \mathrm{L}^{-1}$ dNTPs, $1 \mathrm{U}$ of TaqDNA polymerase (Dynazyme II) and $10 \mathrm{ng}$ of template DNA. Reactions were performed in a MJ PTC-100 thermocycler (Peltier ThermalCycler, MJ Research, Massachusetts, USA) Subsequently, $5 \mu \mathrm{L}$ of each amplification mixture were analyzed by agarose gel electrophoresis in TAE buffer $(1.5 \% \mathrm{w} / \mathrm{v})$ containing $1 \mu \mathrm{g} \cdot \mathrm{mL}^{-}$

1 ethidium bromide, by comparison with a known mass standard. After purification, the PCR reactions were quantified with a spectrophotometric method (Biophotometer, Eppendorf). Unfortunately, amplification was not successful for Ruscus, Scilla and Dioscorea (see Li et al. 2011 for problems with the latter genus). Automated DNA sequencing of the three other species was performed directly from the purified PCR products using BigDye Terminator v. 2 chemistry and an ABI310 sequencer (PE-Applied Biosystems, Connecticut, USA). Original sequences were checked for homology with Blast (http://blast.ncbi.nlm.nih. gov/Blast.cgi) and edited with BioEdit v.7.0 (Hall 1999). Original sequences were deposited in GenBank and can be retrieved using the accession number in Additional file 9.

The final dataset consisted of 110 accessions (Additional file 9) and included two species of Asparagaceae and one of Dioscoreaceae that were not present in our plots but added in order not to lose important phylogenetic information caused by the missing sequences of Ruscus, Scilla and Dioscorea, respectively. The above higher-order taxa would have been otherwise not represented. Multiple alignment of the ITS-5.8S dataset was performed with MAFFT v. 7.0 (Katoh and Standley 2013) using the L-INS-i strategy and then carefully checked by visual inspection with BioEdit. Gaps were coded as separate characters according to Simmons and Ochoterena (2000) using FastGap v.1.0.8 (Borchsenius 2009), and appended at the end of the dataset. Tree construction was finally performed using NeighborJoining (NJ) and bootstrap analysis with 1000 replicates, as implemented in PAUP vers. 4.0 (Swofford 2000). NJ is a fast and effective method to infer reliable phylogenetic trees with branch lengths reflecting evolutionary divergence among species (Mihaescu et al. 2009), as shown by the large congruence between our tree and those by APG IV (2016) in terms of topology of the major clades retrieved.

\section{Indices of phylogenetic diversity and structure}

Faith's phylogenetic diversity (PD) metric (Faith 1992) was used to quantify the phylogenetic $\alpha$-diversity of the understorey of each forest plot (based on the full species list, combining the three quadrats) as the total branch length joining the basal node (i.e., the spermatophyte node) to the branch tips of all species in the plot. Faith's 
PD is the simplest measure of the cumulative evolutionary age in a community and is commonly used in conservation and ecological research (Faith 1992; Forest et al. 2007; Rodrigues and Gaston 2002). The Net Relatedness Index (NRI) and the Nearest Taxon Index (NTI) were used to quantify the degree of community weighted phylogenetic relatedness among species within each forest plot. Both indices are measures of phylogenetic divergence (Tucker et al. 2016) successfully used for the assessment of sustainability and health of forest ecosystems (Potter and Koch 2014) or for the impact of forest plantations on understorey phylogenetic structure (Piwczyński et al. 2016). NRI measures the standardized effect size of the mean phylogenetic distance (MPD), which estimates the average phylogenetic relatedness between all possible pairs of taxa in an assemblage; this index is dominated by the deep phylogenetic relationships between taxa since its calculation considers all pairwise distances within the community (Webb 2000; Stadler et al. 2017). NTI is a standardized measure of the branch-tip phylogenetic clustering of the species on the plot (usually indicated as Mean Nearest Taxon Distance, MNTD) and is independent from the arrangement of the higher-level groups in the phylogenetic tree (Webb et al. 2002). Positive values of NRI and NTI indicate that MPD and MNTD, respectively, are lower than expected by chance (null model) and that phylogenetic clustering of species occurs. Conversely, negative values of NRI and NTI result when the observed Mean Phylogenetic Distance and Mean Nearest Taxon Distance are greater than expected by chance, hence indicating phylogenetic over-dispersion or evenness. AsC should have values <1.96 and $>+1.96$ to be significantly divergent from a random phylogenetic structure. To compare the values of the two variables above to null community data, we used a simple null model of randomly drawing species (phylogeny branch tips), holding plot species richness constant as suggested in the Phylocom software (Webb et al. 2008). All phylogenetic metrics were obtained with the package Picante (Kembel et al. 2010) in $R$ vers. 3.4.3 (R Core Team 2017).

\section{Statistical analyses}

Our first aim was to examine the relationship between understorey species richness (USR) and PD along a gradient of overstorey species richness (OSR). To this purpose, we fitted a linear mixed model with normal distribution of the errors, using PD as response variable and OSR and USR as fixed effect terms, focusing on their interaction term and including a random effect term for the overstorey composition. To account for the presence and possible effects of non-dominant admixed tree species and of the variable proportions of the focal species in the OSR was determined at three levels, as: 1) the number of focal tree species contributing to the total basal area for at least 10\% (target species); 2) the total number of focal tree species, including those with basal area $<10 \%$ (focal species), and 3) all tree species with $\mathrm{dbh} \geq 7 \mathrm{~cm}$ reaching the subdominant or dominant layer (up to 10 species).

Next, we explored the effect of OSR on the phylogenetic structure of the understorey, i.e. the NTI and NRI metrics (aim 2). To this purpose we fitted a series of linear mixed models, again with normal distribution of the errors, using OSR as fixed effect (using the same three richness levels described above) and including a random effect term for the overstorey composition. Since NRI and NTI represent standardized measures of MPD and MNTD not related to species richness, we excluded USR from the analyses, as we did not expect any relevance of this factor on the variation of such indexes. In both linear mixed models, the significance of the fixed effect terms and of their interaction term was estimated adopting an ANOVA table, with Satterthwaite approximation for denominator degree of freedom.

To evaluate the importance of the target species identity in the overstorey (aim 3) we set a series of linear models, with normal distribution of the errors, using the presence/ absence data of each of the five target species as explanatory variables. We used the Information Theoretic Approach (Burnham and Anderson 2002) to select the best combination of effects from the global model including all five target species. Models were compared using the corrected Akaike Information Criterion (AICc), with all possible combinations of predictors identified using the "dredge" function in MuMIn (Barton 2016). Based on $\triangle \mathrm{AICc}$ (which represents the difference between each model and the most parsimonious model), we selected all the models with a $\triangle \mathrm{AICc}$ value $<4$, considered to be equally parsimonious (Burnham and Anderson 2002). The coefficients for each target species in the overstorey were averaged from the best-fitting models and significance of the estimated coefficient was calculated with a $\mathrm{z}$ Wald test. In addition, the relative importance was calculated for each species.

All statistical analyses and graphics were generated using R Studio version R 3.4.3 (R Core Team 2017), with the additional packages lme4 (Bates et al. 2015) and MuMIn (Barton 2016).

\section{Results}

\section{Phylogenetic relationships of the understorey}

The ITS-5.8S alignment of the understorey community included 1858 positions of which 1087 were phylogenetically informative. The backbone of the resulting tree (total length $=11,623$ ) was largely congruent with the APG IV (2016) tree for the major angiosperm groups, which were sister to the conifers (Fig. 2). Angiosperms were subdivided in the two monophyletic clades of monocots and eu-dicots, 


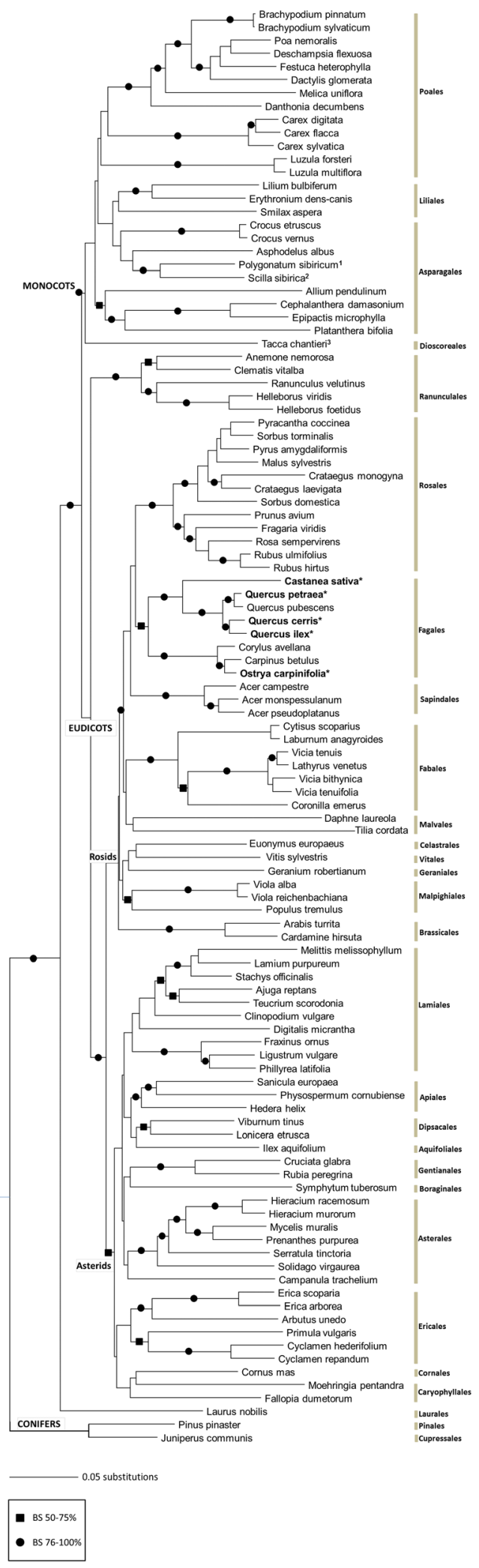

Fig. 2 Neighbor Joining phylogenetic tree of the seed plant species recorded in the 36 plots based on ITS-5.8S DNA sequences. Major angiosperm clades and orders are indicated according to the APG IV system. Focal tree species forming the richness gradient in the plot system are in bold and marked with an asterisk; ${ }^{1}$ replacing Ruscus aculeatus; ${ }^{2}$ Scilla siberica; ${ }^{3}$ Dioscorea communis

which included members of 4 and 24 orders of the APG system, respectively; within the eu-dicots, Ranunculales were sister to the major clades of Asterids and Rosids.

\section{Effects of overstorey species richness}

Model results showed that phylogenetic diversity was strongly dependent on species richness $(P<0.001$; Table 2, Fig. 3). As indicated by a non-significant interaction effect, the strength of this positive relationship did not change along the overstorey tree richness gradient, when considering the target trees only (Fig. 3), the focal trees and all the trees (Additional files 1, 7).

The three models produced consistent results, confirming a strong correlation between PD and USR but no variation related to the number of species in the overstorey, regardless of whether this includes target, focal or all species in the canopy (Table 2, Fig. 3).

Concerning phylogenetic structure, values of both NRI and NTI were mostly positive but non-significant (Fig. 4), indicating randomness with tendency to a clustered pattern. Results in Table 2 showed no effects of overstorey species richness on these response variables $(P>0.05)$, regardless of whether the number of target species, focal species or all species in the canopy was considered as explanatory variable (Additional file 2). Only a few plots with two or three target species and a variable number of other admixed ("all") species showed negative NRI values (Fig. 4).

\section{Effects of overstorey species identity}

The results of the multiple modelling approach and selection to assess the identity effects on USR, PD, NRI and NTI are reported in Additional files 3, 4, 5 and 6, respectively. Phylogenetic diversity was not significantly influenced by the identity of the species in the canopy. However, it was slightly higher in the plots with Ostrya carpinifolia and, even more, in those with Q. cerris (2.4\% higher than intercept) as a consequence of their higher species richness in the understorey $(P=0.085$; Additional file 8$)$. The NRI index was not influenced by the presence/absence of a given species in the overstorey. On the contrary, NTI was significantly influenced by Q. petraea (Table 3). Indeed, the mean NTI index was higher in plots with this oak species present (Fig. 5), indicating a closer relatedness between species (branch-tips of the phylogenetic tree) in the understorey of plots including this tree. 
Table 2 ANOVA table from the linear mixed models evaluating the effect of overstorey species richness (OSR) on the relationship between USR and PD in the understorey, and on $\mathrm{NRI}$ and NTI of the understorey

\begin{tabular}{lrrrrrrr}
\hline \multicolumn{1}{l}{ Response } & \multicolumn{1}{l}{ Term } & Sum Sq & Mean Sq & NumDF & DenDF & $F$ value & $P$-value \\
\hline PD & USR & $4,606,196$ & $4,606,196$ & 1 & 30.984 & 49.261 & $<0.001$ *** \\
& OSR & 146,464 & 146,464 & 1 & 30.44 & 1.566 & 0.220 \\
& USR: OSR & 169,664 & 169,664 & 1 & 31.074 & 1.814 & 0.188 \\
NRI & OSR & 0.297 & 0.297 & 1 & 33.000 & 0.443 & 0.511 \\
NTI & OSR & 0.119 & 0.119 & 1 & 15.140 & 0.276 & 0.607
\end{tabular}

Sum Sq sum of squares, Mean Sq mean squares, NumDF numerator degree of freedom, DenDF denominator degree of freedom

Significance code: ${ }^{* * * \prime}$ highly significant

\section{Discussion}

In relation to our first aim, results showed that the phylogenetic diversity of the understorey was invariably dependent on species richness, and that the strength of this relationship was not influenced by the number of species in the forest canopy. In previous studies showing decoupling between species richness and evolutionary diversity, different causes were involved, including large-scale eco-geographical patterns and environmental drivers such as climate and soil type (Forest et al. 2007; Knapp et al. 2008; Potter and Woodall 2014). In contrast, evidence from more local studies in forest communities under relatively homogeneous conditions supports our finding that PD is almost a linear function of species richness (Qian et al. 2014; Selvi et al. 2016). In our model

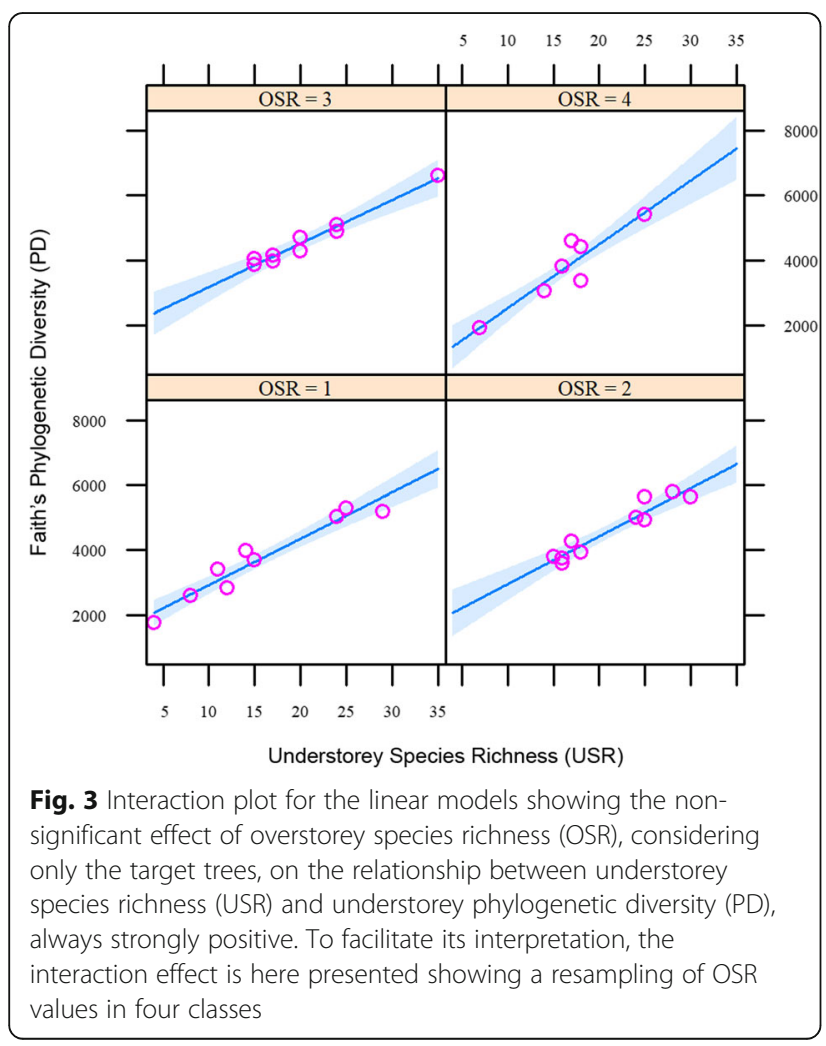

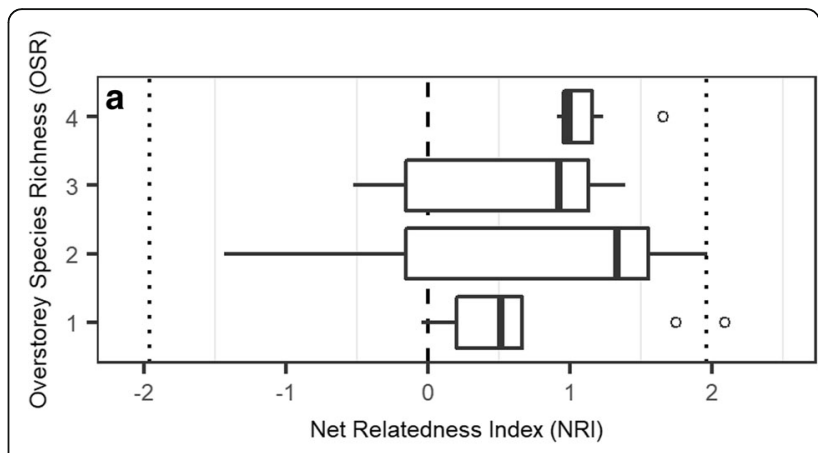

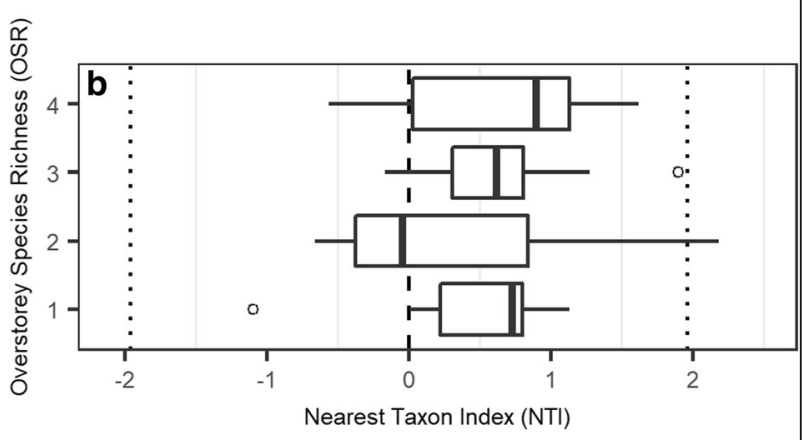

Fig. 4 Boxplots showing variation of $\mathbf{a}) \mathrm{NRI}$, and $\mathbf{b}$ ) NTI, in relation to overstorey species richness expressed as number of target species. The significance thresholds for significantly diverging values of NRI and NTI are indicated with dotted lines (+ 1.96 and -1.96$)$

system, the slope of this function linking the two understorey variables is not affected by species richness in the overstorey, hence the latter cannot serve as an indicator of the amount of plant evolutionary diversity at the forest floor. A positive decoupling of PD from USR along the OSR gradient would have occurred if the species that "enter" in the understorey of 3- or 4-species mixtures plots added a proportionally greater amount of evolutionary diversity than those growing in pure stands or 2species mixtures. Our non-significant result was likely due to incorrect prediction that more distantly related species are more able to use different niches, and/or to the inconsistency of the environmental heterogeneity hypothesis as already suggested in other studies on overstoreyunderstorey diversity relationships in temperate forests (Barbier et al. 2008; Ampoorter et al. 2016).

In terms of phylogenetic structure, we found that randomness was the prevalent pattern in the stands examined here, showing that the understorey is formed by taxa that are related to each other as predicted by chance, both at species-level and deeper phylogenetic levels. However, the mainly positive values of NRI and NTI indicated a tendency to clustering which may be due to the coexistence of loosely related species adapted to the common set of conditions in our plots, such as low light availability, soil characteristics and, possibly, 
Table 3 Results for the estimate of model coefficients and their significance to assess the effect of overstorey species identity on PD, NTI e NRI

\begin{tabular}{|c|c|c|c|c|c|c|}
\hline $\begin{array}{l}\text { Resp. } \\
\text { variable }\end{array}$ & Term & Estimate & Std. Error & Adjusted SE & $z$ value & $P$-value \\
\hline \multirow[t]{6}{*}{$\mathrm{PD}$} & (Intercept) & 4250.938 & 187.236 & 194.237 & 21.885 & $<0.001^{* * *}$ \\
\hline & Quercus cerris & 103.309 & 208.580 & 212.779 & 0.486 & 0.627 \\
\hline & Quercus ilex & -116.350 & 222.404 & 226.656 & 0.513 & 0.608 \\
\hline & Ostrya carpinifolia & 90.390 & 201.642 & 205.862 & 0.439 & 0.661 \\
\hline & Quercus petraea & -8.484 & 102.163 & 105.942 & 0.080 & 0.936 \\
\hline & Castanea sativa & -7.441 & 100.635 & 104.396 & 0.071 & 0.943 \\
\hline \multirow[t]{6}{*}{ NRI } & (Intercept) & 0.779 & 0.140 & 0.146 & 5.349 & $<0.001^{* * *}$ \\
\hline & Quercus cerris & -0.070 & 0.151 & 0.154 & 0.455 & 0.649 \\
\hline & Ostrya carpinifolia & 0.051 & 0.134 & 0.137 & 0.370 & 0.712 \\
\hline & Quercus petraea & 0.026 & 0.101 & 0.104 & 0.254 & 0.799 \\
\hline & Quercus ilex & 0.017 & 0.088 & 0.091 & 0.182 & 0.856 \\
\hline & Castanea sativa & 0.012 & 0.081 & 0.084 & 0.140 & 0.889 \\
\hline \multirow[t]{6}{*}{ NTI } & (Intercept) & 0.546 & 0.117 & 0.122 & 0.471 & $<0.001^{* * *}$ \\
\hline & Quercus petraea & 0.527 & 0.165 & 0.172 & 3.070 & $0.002^{* *}$ \\
\hline & Castanea sativa & -0.018 & 0.078 & 0.080 & 0.227 & 0.820 \\
\hline & Ostrya carpinifolia & -0.013 & 0.071 & 0.073 & 0.178 & 0.859 \\
\hline & Quercus ilex & 0.012 & 0.069 & 0.071 & 0.170 & 0.865 \\
\hline & Quercus cerris & -0.012 & 0.068 & 0.070 & 0.165 & 0.869 \\
\hline
\end{tabular}

Significance codes: ${ }^{* * * * \prime}$ highly significant; ${ }^{* * * \prime}$ significant

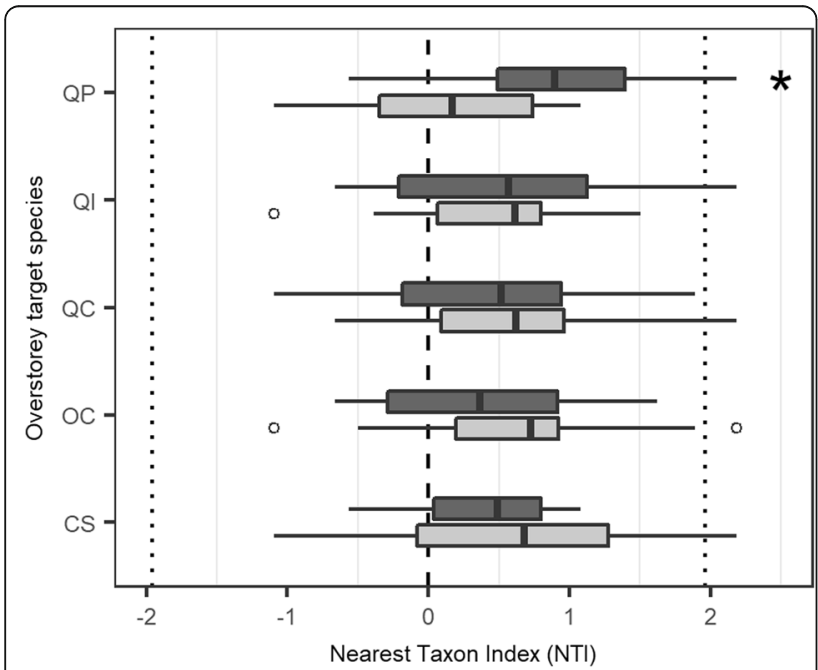

Fig. 5 Variation of Nearest Taxon Index (NTI) in plots with presence (dark grey) or absence (light grey) of the five target species (CS = Castanea sativa; OC = Ostrya carpinifolia; $\mathrm{QC}=$ Quercus cerris; $\mathrm{Q} \mathrm{I}=$ Quercus ilex; $\mathrm{QP}=$ Quercus petraea). The significance thresholds for significantly diverging values of NRI and NTI are indicated with dotted lines (+ 1.96 and -1.96$)$. The symbol * indicates the species for which a significant difference of NTI values according to presence/absence of the species in the overstorey was detected the legacy effects of the cyclic disturbance caused by centuries of coppice management.

Secondly, our results indicate that a potential biotic driver such as overstorey species diversity has inconsistent effects on the phylogenetic structure of the understorey community, suggesting again that the mixing of more tree species does not necessarily increase environmental heterogeneity or resource availability in the understorey. This is in line with recent findings by Sercu et al. (2017) who found that heterogeneity of light availability at the forest floor is not higher in mixed stands, and that abiotic niche variability may be independent from overstorey species richness. The non-significant influence of overstorey richness (as well as functional dispersion) on understorey species richness recently observed in European forests (Ampoorter et al. 2014, 2015, 2016) could also be related to the inconsistency of the environmental heterogeneity hypothesis. As in these studies, our finding can be better interpreted in light of the novel environment creation hypothesis, by which the new habitat conditions created by the mixing of more tree species ("true" diversity effect; Ball et al. 2008) do not allow to predict variations in species richness, composition and phylogenetic structure of the understorey, compared to the component species pure stands. In interpreting the lack of overstorey diversity effect observed here, however, the possible role of the shrub layer on understorey vegetation should be acknowledged. Though this layer was not considered in our study for practical reasons, it still represents a constitutive element of southern European thermophilous deciduous forests (Barbati et al. 2007) and most of our plots (Carrari et al. 2016). Shrubs may contribute to niche differentiation and facilitation, but negative effects on the abundance and diversity of the understorey by competition for light, water and soil nutrients can occur (Barbier et al. 2009). Hence, whether these minor woody species can contribute in influencing the phylogenetic structure of the ground forest vegetation cannot be excluded and requires further investigation.

When looking at the effects of overstorey species identity, the marginally positive effect of Q. cerris on USR may have a number of reasons. One is the later budburst of this oak species compared with the other focal trees in our plots (Gellini and Grossoni 1997), which means more light availability at the forest floor during the spring. More significant was the effect of Q. petraea on the NTI index. The presence of the sessile oak in the overstorey was found to be associated with an increase of clustering at the species-level, while the non-significant response of NRI indicated that the deeper phylogenetic nodes of the understorey community under this tree were not affected. In plant communities, clustering can result from various constraints among which habitat filtering driven by biotic and abiotic disturbance (e.g. fire; Verdú and Pausas 2007) 
or limiting environmental factors along ecological gradients (e.g. altitude; Qian et al. 2014; drought; Nagaraju Shivaprakash et al. 2018) or successional stages (Stadler et al. 2017). On the other hand, it can also result from competitive exclusion in non-restrictive, stable habitats (Mayfield and Levine 2010). In temperate forests of North America, for example, clustering was predominant in favorable conditions, while evenness was prevalent in stands from harsher environments (Potter and Koch 2014). Evidence about the auto-ecology and morphofunctional traits of Q. petraea support this relationship, since in central Italy the sessile oak forms pure or mixed forests only in favorable conditions in terms of humidity, soil depth and fertility, and creates a habitat which supports mesophilous geophytes and hemicryptophytes in the herb layer (Pignatti 1998; Blasi 2010). Hence, it is most unlikely that this widespread European tree can act as a biotic filter sieving stress-tolerant understorey species with phylogenetically conserved adaptive traits. Instead, it can be assumed that interspecific competition among plants under this tree is stronger than in the stands dominated by our other target species in less favorable conditions. For example, factors such as the heavy shading by the evergreen holm-oak (Quercus ilex), the soil acidification driven by the sweet chestnut (Castanea sativa), the dryer soil under the Turkey oak (Q. cerris) or the steep slopes often supporting $O$. carpinifolia are likely to limit interspecific competition in the understorey. Competitive exclusion in environments with wide resource availability can decrease species diversity (Grime 1973; Gross et al. 2000) and can also result in phylogenetic clustering under the Niche Conservatism assumption. In fact, the set of morphological and functional traits enabling some species to exploit the resources better than others will be likely the result of a close phylogenetic relatedness between them. Hence, the understorey species under Q. petraea are more closely related to each other than expected by chance and are likely to share common traits that give them a competitive advantage in the use of the resources.

\section{Conclusions}

Due to its observational nature and small number of plots, this study cannot address the causal effects between overstorey tree species diversity/identity on understorey phylogenetic structure. Potential confounding factors are the small-scale variation of site conditions between plots and the presence of a significant shrub layer. Species diversity and identity effects in the latter have never been considered to date, though they may potentially interact with those driven by the overstorey trees and ultimately affect the understorey in an unpredictable way.

Despite these limits, however, our study opens a first window on the phylogenetic structure of the understorey vegetation of thermophilous deciduous forests and provides original genetic data for its herbaceous species. Also, it represents a first attempt to explore the relationships between forest overstorey and understorey from a phylogenetic community perspective, using an ad-hoc system of plots in a native forest ecosystem inside protected areas. In detecting no influence of tree species richness, we suggest that mixed stands may not harbor a phylogenetically more even or diverse understorey than monocultures. The presence of an important forest tree, $Q$. petraea, was instead found to increase the species-level evolutionary relatedness in the understorey, suggesting species identity to be more important than species richness. This is not in line with evidence from non-native tree plantations in central Europe, where species identity did not affect the understorey phylogenetic structure (Piwczyński et al. 2016). Hence, further studies on wider geographic and environmental scales are needed to better understand the relationship between overstorey and understorey from an evolutionary standpoint. In particular, the influence of given species combinations and single forest trees with a relevant role for silviculture should be analyzed in relation to the site conditions in which they are found. Evidence from these studies may help to fill the current gap between the mostly theoretical field of plant community phylogenetics and forest management.

\section{Additional files}

Additional file 1: ANOVA table from the linear models evaluating the effect of overstorey species richness (OSR) on the relationship between Species Richness (SR) and Faith's phylogenetic diversity (PD) in the understorey, in the two cases in which OSR includes only the focal species or all species in the canopy. (DOCX $14 \mathrm{~kb}$ )

Additional file 2: ANOVA table from the linear models evaluating the effect of overstorey species richness (OSR) on Net Relatedness Index (NRI) and Nearest Taxon Index (NTI) of the understorey, in the two cases in which OSR is described accounting the focal species, or all species in the canopy. (DOCX $14 \mathrm{~kb}$ )

Additional file 3: Model selection table from analyses of the effect of target species identity in the overstorey ( $C S=$ Castanea sativa; $\mathrm{OC}=$ Ostrya carpinifolia; $\mathrm{QC}=$ Quercus cerris; $\mathrm{Ql}=$ Quercus ilex; $\mathrm{QP}=$ Quercus petraea) on the Species Richness of the understorey. Only models with a $\triangle \mathrm{AICc}<4$ were used to calculate the averaged coefficient estimates. (DOCX $21 \mathrm{~kb}$ )

Additional file 4: Model selection table from analyses of the effect of target species identity in the overstorey (CS = Castanea sativa; $\mathrm{OC}=$ Ostrya carpinifolia; $\mathrm{QC}=$ Quercus cerris; $\mathrm{Q} \mathrm{I}=$ Quercus ilex; $\mathrm{QP}=$ Quercus petraea) on the Faith's phylogenetic diversity (PD) of the understorey. Only models with a $\triangle \mathrm{AICC}<4$ were used to calculate the averaged coefficient estimates. (DOCX $21 \mathrm{~kb}$ )

Additional file 5: Model selection table from analyses on the effect of the target species identity in the overstorey ( $\mathrm{CS}=$ Castanea sativa; $\mathrm{OC}=$ Ostrya carpinifolia; $\mathrm{QC}=$ Quercus cerris; $\mathrm{QI}=$ Quercus ilex; $\mathrm{QP}=$ Quercus petraea) on the Net Relatedness Index (NRI) of the understorey. Only models with a $\triangle \mathrm{AIC}<4$ were used to calculate the averaged coefficient estimates. (DOCX $21 \mathrm{~kb}$ )

Additional file 6: Model selection table from analyses of the effects of target species identity in the overstorey (CS = Castanea sativa; $\mathrm{OC}=$ Ostrya carpinifolia; $\mathrm{QC}=$ Quercus cerris; $\mathrm{Ql}=$ Quercus ilex; $\mathrm{QP}=$ Quercus petraea) on the Nearest Taxon Index (NTI) of the 
understorey. Only models with a $\Delta \mathrm{AICc}<4$ were used to calculate the averaged coefficient estimates. (DOCX $21 \mathrm{~kb}$ )

Additional file 7: Interaction plot for the linear mixed models showing the non-significant effect of overstorey species richness (OSR) on the relationship between species richness and phylogenetic diversity (PD) in the understorey, always strongly positive. OSR was described considering A) all of the five focal trees and B) "all trees" with $\mathrm{dbh} \geq 7 \mathrm{~cm}$ reaching the subdominant or dominant layer. In order to facilitate the interpretation of the interaction term the figures show a resampling of OSR values in three and four classes respectively. (DOCX $153 \mathrm{~kb}$ )

Additional file 8: Effect of overstorey species identity on understorey species richness (A), phylogenetic diversity (B) and Net Relatedness Index (C). Species abbreviations are as in Fig. 5. (DOCX $143 \mathrm{~kb}$ )

Additional file 9: List of seed plants (excluding ferns) recorded in the plots, with GenBank accessions used for tree construction and subsequent calculation of phylogenetic diversity metrics. Originally sequenced taxa are in bold; for these species vouchers details are given. (DOCX $27 \mathrm{~kb}$ )

\section{Abbreviations}

AICc: Akaike information criterion; APG: Angiosperm phylogeny group; MNTD: Mean nearest taxon distance; MPD: Mean phylogenetic distance; NRI: Net Relatedness Index; NTI: Nearest taxon index; OSR: Overstorey species richness; PD: Faith's phylogenetic diversity metric; USR: Understorey species richness

\section{Acknowledgements}

Authors wish to acknowledge Filippo Bussotti and Martina Pollastrini (Firenze) for help during field work for the FunDIV Europe Project and discussion of the data.

\section{Authors' contributions}

$A C$ and FS conceived the work; $A C, L B$ and FS acquired the data; $A C$ and $L L$ analyzed the data; FS, AC and LL drafted the manuscript; EA, KV and LL critically revised the article and contributed to the drafting of the manuscript. All authors read and approved the final manuscript.

\section{Funding}

Plot establishment and understorey data collection were performed in the framework of FunDivEUROPE, an FP7/2007-2013 project under agreement $n^{\circ} 265171$. Laboratory work was supported by research grants to AC and FS from the University of Florence and the Italian Ministry for University and Scientific Research. KV was supported by an ERC Consolidator Grant (PASTFORWARD-project; No: 614839).

\section{Availability of data and materials}

The datasets used and/or analysed during the current study are available from the corresponding author on reasonable request.

\section{Ethics approval and consent to participate}

Not applicable.

\section{Consent for publication}

Not applicable.

\section{Competing interests}

The authors declare that they have no competing interests.

\section{Author details}

${ }^{1}$ Department of Biology, University of Florence, Florence, Italy. ${ }^{2}$ Department of Environment, Forest and Nature Lab, Ghent University, Ghent, Belgium. ${ }^{3}$ Department of Agriculture, Food, Environment and Forestry, Laboratories of Botany, University of Florence, Florence, Italy.

Received: 24 October 2018 Accepted: 19 June 2019 Published online: 19 July 2019

\section{References}

Ampoorter E, Baeten L, Koricheva J, Vanhellemont M, Verheyen K (2014) Do diverse overstoreys induce diverse understoreys? Lessons learnt from an experimental-observational platform in Finland. For Ecol Manag 318:206-215. https://doi.org/10.1016/.j.foreco.2014.01.030

Ampoorter E, Baeten L, Vanhellemont M, Bruelheide H, Scherer-Lorenzen M, Baasch A, Erfmeier A, Hock M, Verheyen K (2015) Disentangling tree species identity and richness effects on the herb layer: first results from a German tree diversity experiment. J Veg Sci 26:742-755. https://doi. org/10.1111/jvs. 12281

Ampoorter E, Selvi F, Auge H, Baeten L, Berger S, Carrari E, Coppi A, Fotelli M, Radoglou K, Setiawan NN, Vanhellemont M, Verheyen K (2016) Driving mechanisms of overstorey-understorey diversity relationships in European forests. Perspect Plant Ecol Evol Syst 19:21-29. https://doi.org/10.1016/j. ppees.2016.02.001

APG IV (2016) An update of the angiosperm phylogeny group classification for the orders and families of flowering plants. Bot J Linn Soc 181:1-20. https:// doi.org/10.1111/boj.12385

Arroyo Rodríguez V, Cavender-Bares J, Escobar F, Melo FPL, Tabarelli M, Santos BA (2012) Maintenance of tree phylogenetic diversity in a highly fragmented rain forest. J Ecol 100:702-711. https://doi.org/10.1111/j.13652745.2011.01952.x

Baeten L, Verheyen K, Wirth C, Bruelheide H, Bussotti F, Finer L, Jaroszewicz B, Selvi F, Valladaresh F, Allan E, Ampoorter E, Auge H, Avacariei D, Barbaro L, Barnoaiea I, Bastias CC, Bauhus J, Beinhoff C, Benavides R, Benneter A, Berger S, Berthold F, Boberg J, Bonal D, Braggernann W, Carnol M, Castagneyrol B, Charbonnier Y, Checko E, Coomess D, Coppi A, Dalmaris E, Danila G, Dawud SM, de Vries W, De Wandeler H, Deconchat M, Domisch T, Duduman G, Fischer M, Fotelli M, Gessler A, Gimeno TE, Granier A, Grossiord C, Guyot V, Hantsch L, Hattenschwiler S, Hector A, Hermy M, Holland V, Jactel H, Joly FX, Jucker T, Kolb S, Koricheva J, Lexer MJ, Liebergesell M, Milligan H, Muller S, Muys B, Nguyen D, Nichiforel L, Pollastrini M, Proulx R, Rabasa S, Radoglou K, Ratcliffe S, Raulund-Rasmussen K, Seiferling I, Stenlid J, Vesterdal L, von Wilpert K, Zavala MA, Zielinski D, Scherer-Lorenzen M (2013) A novel comparative research platform designed to determine the functional significance of tree species diversity in European forests. Perspect Plant Ecol Evol Syst 15:281-291. https://doi.org/10.1016/j.ppees.2013.07.002

Ball BA, Hunter MD, Kominoski JS, Swan CM, Bradford MA (2008) Consequences of non-random species loss for decomposition dynamics: experimental evidence for additive and non-additive effects. J Ecol 96:303-313. https://doi. org/10.1111/j.1365-2745.2007.01346.x

Barbati A, Corona P, Marchetti M (2007) European Forest Types Categories and types for sustainable forest management reporting and policy, EEA Technical report no. 9/2006, 2nd edn. European Environment Agency, Copenhagen

Barbier S, Chevalier R, Loussot P, Bergès L, Gosselin F (2009) Improving biodiversity indicators of sustainable forest management: tree genus abundance rather than tree genus richness and dominance for understory vegetation in French lowland oak hornbeam forests. For Ecol Manag 258:S176-S186

Barbier S, Gosselin F, Balandier P (2008) Influence of tree species on understorey vegetation diversity and mechanisms involved - a critical review for temperate and boreal forests. For Ecol Manag 254:1-15. https://doi.org/10. 1016/j.foreco.2007.09.038

Barton K (2016) MuMIn: multi-Model Inference. R package version 1.15.6. https:// CRAN.R-project.org/package=MuMIn. Accessed 01 Oct 2018

Bates D, Mächler M, Bolker B, Walker S (2015) Fitting linear mixed-effects models using Ime4. J Stat Softw 67:1-48. https://doi.org/10.18637/jss.v067.01

Blasi C (2010) La Vegetazione d'Italia. Palombi, Roma

Borchsenius F (2009) FastGap, version 1.2. Department of Biological Sciences, University of Aarhus, Denmark. https://www.aubot.dk/FastGap_home.htm. Accessed 01 Oct 2018

Burnham KP, Anderson DR (2002) Model selection and multimodel inference - a practical information-theoretic approach, 2nd edn. Springer-Verlag, Berlin

Bussotti F, Coppi A, Pollastrini M, Feducci M, Baeten L, Scherer-Lorenzen M, Verheyen K, Selvi F (2012) Le aree forestali italiane di FunDivEUROPE: un nuovo progetto FP7 sul significato funzionale della biodiversità forestale in Europa. Forest@ 9:251-259. https://doi.org/10.3832/efor0704-009

Cadotte MW, Dinnage R, Tilman D (2013) Phylogenetic diversity promotes ecosystem stability. Ecology 93:S223-S233

Carrari E, Ampoorter E, Coppi A, Selvi F (2016) Diversity of secondary woody species in relation to species richness and cover of dominant trees in thermophilous deciduous forests of central Italy. Scand J For Res 31:484-494. https://doi.org/10.1080/02827581.2015.1081981

Doyle JJ, Doyle JL (1990) Isolation of plant DNA from fresh tissue. Focus 12:13-15 
Faith DP (1992) Conservation evaluation and phylogenetic diversity. Biol Conserv 61:1-10. https://doi.org/10.1016/0006-3207(92)91201-3

Faith DP, Magallon S, Hendry AP, Conti E, Yahara T, Donoghue MJ (2010) Evosystem services: an evolutionary perspective on the links between biodiversity and human well-being. Curr Opin Environ Sustain 2:66-74. https://doi.org/10.1016/j.cosust.2010.04.002

Forest F, Grenyer R, Rouget M, Davies TJ, Cowling RM, Faith DP (2007) Preserving the evolutionary potential of floras in biodiversity hotspots. Nature 445:757760. https://doi.org/10.1038/nature05587

Garnier E, Navas ML, Grigulis K (2015) Plant functional diversity. Oxford University Press, UK

Gellini R, Grossoni P (1997) Botanica Forestale vol 2. Angiosperme, Cedam Padova

Gilliam FS (2007) The ecological significance of the herbaceous layer in temperate forest ecosystems. BioScience 57:845-858. https://doi.org/10.1641/B571007

Gilliam FS (2014) The herbaceous layer in forests of eastern North America. Oxford University Press, New York

Grime JP (1973) Competitive exclusion in herbaceous vegetation. Nature 242: 344-347. https://doi.org/10.1038/242344a0

Gross KL, Willig MR, Gough L, Inouye R, Cox SB (2000) Patterns of species diversity and productivity at different spatial scales in herbaceous plant communities. Oikos 89:417-427. https://doi.org/10.1034/j.1600-0706.2000.890301.x

Hall TA (1999) BioEdit: a user-friendly biological sequence alignment editor analysis program for windows 95/98/NT. Nucleic Acids Symp Ser 41:95-98

Harvey PH, Pagel MD (1991) The comparative method in evolutionary biology. In: Oxford series in ecology and evolution, vol 1. Oxford University Press, UK

Hollingsworth PM, Graham SW, Little DP (2011) Choosing and using a plant DNA barcode. PLoS One 6(5):e19254. https://doi.org/10.1371/journal.pone.0019254

Huston M (1979) A general hypothesis of species diversity. Am Nat 113:81-101. https://doi.org/10.1086/283366

Katoh K, Standley DM (2013) MAFFT multiple sequence alignment software version 7: improvements in performance and usability. Mol Biol Evol 30:772780. https://doi.org/10.1093/molbev/mst010

Kembel SW, Cowan PD, Helmus MR, Cornwell WK, Morlon H, Ackerly DD (2010) Picante: $\{R\}$ tools for integrating phylogenies and ecology. Bioinformatics 26 : 1463-1464. https://doi.org/10.1093/bioinformatics/btq166

Kirwan L, Connolly J, Finn J, Brophy C, Lüscher A, Nyfeler D, Sebastia MT (2009) Diversity-interaction modeling: estimating contributions of species identities and interactions to ecosystem function. Ecology 90:2032-2038. https://doi. org/10.1890/08-1684.1

Knapp S, Kühn I, Schweiger O, Klotz S (2008) Challenging urban species diversity: contrasting phylogenetic patterns across plant functional groups in Germany. Ecol Lett 11:1054-1064. https://doi.org/10.1111/j.1461-0248.2008.01217.x

Lapiedra O, Sol D, Traveset A, Vilà M (2015) Random processes and phylogenetic loss caused by plant invasions. Glob Ecol Biogeogr 24:774-785. https://doi. org/10.1111/geb.12310

Levine JM, Hille Ris Lambers J (2009) The importance of niches for the maintenance of species diversity. Nature 46:254-257. https://doi.org/10.1038/nature08251

Li D, Trotta L, Marx HE, Allen JM, Sun M, Soltis DE, Soltis P, Guralnick RP, Baiser B (2018) For comparing phylogenetic diversity among communities, go ahead and use synthesis phylogenies. BioRxiv. https://doi.org/10.1101/370353

Li DZ, Gao LM, Li HT, Wang H, Ge XJ, Liu JQ, Chen ZD, Zhou SL, Chen SL, Yang JB, Fu CX, Zeng CX, Yan HF, Zhu YJ, Sun YS, Chen SY, Zhao L, Wang K, Yang T, Duan GW (2011) Comparative analysis of a large dataset indicates that internal transcribed spacer (ITS) should be incorporated into the core barcode for seed plants. Proc Natl Acad Sci U S A 49:19641-19646. https:// doi.org/10.1073/pnas.1104551108

Mayfield MM, Levine JM (2010) Opposing effects of competitive exclusion on the phylogenetic structure of communities. Ecol Lett. https://doi.org/10.1111/j. 1461-0248.2010.01509.x

Mihaescu R, Levy D, Pachler L (2009) Why neighbour-joining works. Algorithmica 59:1-24. https://doi.org/10.1007/s00453-007-9116-4

Ministerial Conference on the Protection of Forests in Europe (2011) State of Europe's forests 2011 - Status and trends in Sustainable Forest Management in Europe. https://www.foresteurope.org/documentos/State_of_Europes_ Forests_2011_Report_Revised_November_2011.pdf. Accessed 01Oct 2018

Mölder A, Bernhardt-Römermann M, Schmidt W (2008) Herb-layer diversity in deciduous forests: raised by tree richness or beaten by beech? For Ecol Manag 256:272-281. https://doi.org/10.1016/j.foreco.2008.04.012

Muller RN (2014) Nutrient relations of the herbaceous layer in deciduous forest ecosystems. In: Gilliam FS (ed) the herbaceous layer in forests of eastern North America. Oxford University Press, New York, pp 13-34
Nagaraju Shivaprakash K, Ramesh BR, Umashaanker R, Dayanandan S (2018) Functional trait and community phylogenetic analyses reveal environmental filtering as the major determinant of assembly of tropical forest tree communities in the Western Ghats biodiversity hotspot in India. For Ecosyst 5:25. https://doi.org/10.1186/s40663-018-0144-0

Pignatti S (1998) I boschi d'Italia: Sinecologia e biodiversità. [the forests of Italy: synecology and biodiversity]. Utet. Italian, Torino

Piwczyński M, Puchałka R, Ulrich W (2016) Influence of tree plantations on the phylogenetic structure of understorey plant communities. For Ecol Manag 376:231-237. https://doi.org/10.1016/j.foreco.2016.06.011

Potter KM, Koch FH (2014) Phylogenetic community structure of forests across the conterminous United States: regional ecological patterns and forest health implications. For Sci 60:851-861. https://doi.org/10.5849/forsci.13-115

Potter KM, Woodall CW (2014) Does biodiversity make a difference? Relationships between species richness, evolutionary diversity and aboveground live tree biomass across U.S. forests. For Ecol Manag 321:117-129. https://doi.org/10. 1016/j.foreco.2013.06.026

Prinzing A, Durka W, Klotz S, Brandl R (2001) The niche of higher plants: evidence for phylogenetic conservatism. Theory Proc R Soc Lond B 268:2383-2389. https://doi.org/10.1098/rspb.2001.1801

Qian H, Hao Z, Zhang J (2014) Phylogenetic structure and phylogenetic diversity of angiosperm assemblages in forests along an elevational gradient in Changbaishan, China. J PI Ecol:1-14. https://doi.org/10.1093/jpe/rtt072

R Core Team (2017) A Language and Environment for Statistical Computing. R Foundation for Statistical Computing, Vienna http://www.R-project.org. Accessed 01 Oct 2018

Rodrigues ASL, Gaston KJ (2002) Maximising phylogenetic diversity in the selection of networks of conservation areas. Biol Conserv 105:103-111. https://doi.org/10.1016/S0006-3207(01)00208-7

Selvi F, Carrari E, Coppi A (2016) Impact of pine invasion on the taxonomic and phylogenetic diversity of a relict Mediterranean forest ecosystem. For Ecol Manag 367:1-11. https://doi.org/10.1016/j.foreco.2016.02.013

Sercu BK, Baeten L, van Coillie F, Martel A, Lens L, Verheyen K, Bonte D (2017) How tree species identity and diversity affect light transmittance to the understorey in mature temperate forests. Ecol Evol. https://doi.org/10. 1002/ece 3.3528

Silvertown J (2004) Plant coexistence and the niche. Trends Ecol Evol 19:605-611. https://doi.org/10.1016/j.tree.2004.09.003

Simmons MP, Ochoterena H (2000) Gaps as characters in sequence-based phylogenetic analyses. Syst Biol 49:369-381. https://doi.org/10.1093/ sysbio/49.2.369

Srivastava DS, Cadotte MW, MacDonald AAM, Marushia RG, Mirotchnicket N (2012) Phylogenetic diversity and the functioning of ecosystems. Ecol Lett 15:637-648. https://doi.org/10.1111/j.1461-0248.2012.01795.x

Stadler J, Klotz S, Brandl R, Knapp S (2017) Species richness and phylogenetic structure in plant communities: 20 years of succession. Web Ecol 17:37-46. https://doi.org/10.5194/we-17-37-2017

Swofford DL (2000) PAUP* 4.0: Phylogenetic analysis using parsimony ${ }^{*}$ and other methods), version 4.0. Sinauer, Sunderland

Tallents LA, Lovett JC, Hall JB, Hamilton AC (2005) Phylogenetic diversity of forest trees in the Usambara mountains of Tanzania: correlations with altitude. Bot J Linn Soc 149:217-228

Tucker CM, Cadotte MW, Carvalho SB, Davies TJ, Ferrier S, Fritz SA, Grenyer R, Helmus MR, Jin LS, Mooers AO, Pavoine S, Purschke O, Redding DW, Rosauer DF, Winter M, Mazel F (2016) A guide to phylogenetic metrics for conservation, community ecology and macroecology. Biol Rev 92:698-715. https://doi.org/10.1111/brv.12252

Verdú M, Pausas JG (2007) Fire drives phylogenetic clustering in Mediterranean Basin woody plant communities. J Ecol 95:1316-1323. https://doi.org/10. 1111/j.1365-2745.2007.01300.x

Verstraeten G, Baeten L, De Frenne P, Vanhellemont M, Thomaes A, Boonen W, Muys B, Verheyen K (2013) Understorey vegetation shifts following the conversion of temperate deciduous forest to spruce plantation. For Ecol Manag 289:363-370. https://doi.org/10.1016/j.foreco.2012.10.049

Vockenhuber EA, Scherber C, Langenbruch C, Meiner M, Seidel D, Tscharntke T (2011) Tree diversity and environmental context predict herb species richness and cover in Germany's largest connected deciduous forest. Perspect Plant Ecol Evol Syst 13:111-119. https://doi.org/10.1016/j.ppees.2011.02.004

Webb CO (2000) Exploring the phylogenetic structure of ecological communities: an example for rain forest trees. Am Nat 156:145-155. https://doi.org/10. $1086 / 303378$ 
Webb CO, Ackerly DD, Kembel SW (2008) Phylocom: software for the analysis of phylogenetic community structure and trait evolution. Bioinformatics 24: 2098-2100. https://doi.org/10.1093/bioinformatics/btn358

Webb CO, Ackerly DD, McPeek MA, Donoghue MJ (2002) Phylogenies and community ecology. Annu Rev Ecol Evol Syst 33:475-505. https://doi.org/10 1146/annurev.ecolsys.33.010802.150448

Welch NT, Belmont JM, Randolph JC (2007) Summer ground layer biomass and nutrient contribution to above-ground litter in an Indiana temperate deciduous forest. Am Midl Nat 157:11-26. https://doi.org/10.1674/00030031(2007)157[11:SGLBAN]2.0.CO;2

White TJ, Bruns T, Lee S, Taylor J (1990) Amplification and direct sequencing of fungal ribosomal RNA genes for phylogenetics. In: Innis MA, Gelfand DH, Sninsky JJ, White JW (eds) PCR protocols: a guide to methods and applications. Academic Press, New York, pp 315-322. https://doi.org/10.1016/ b978-0-12-372180-8.50042-1

Wiens JJ, Ackerly DD, Allen AP, Anacker BL, Buckley LB, Cornell HV, Damschen El, Davies TJ, Grytne JA, Harrison SP, Hawkins BA, Holt RD, McCain CM, Stephens PR (2010) Niche conservatism as an emerging principle in ecology and conservation biology. Ecol Lett 13:1310-1324. https://doi.org/10.1111/j.14610248.2010.01515.x

Zhang W, Huang D, Wang R, Liu J, Du N (2016) Altitudinal patterns of species diversity and phylogenetic diversity across temperate mountain forests of northern China. PLoS One 11(7):e0159995. https://doi.org/10.1371/journal. pone.0159995

\section{Submit your manuscript to a SpringerOpen ${ }^{\circ}$ journal and benefit from:}

- Convenient online submission

- Rigorous peer review

- Open access: articles freely available online

- High visibility within the field

- Retaining the copyright to your article

Submit your next manuscript at $\boldsymbol{\nabla}$ springeropen.com 